\title{
MULHER NEGRA: INTERSECCIONANDO GÊNERO, RAÇA, CLASSE, CULTURA E EDUCAÇÃO
}

\author{
Ana Cláudia Lemos Pacheco* \\ Martha Maria Brito Nogueira**
}

\begin{abstract}
RESUMO
Este artigo analisa a trajetória de uma mulher negra de classe popular, baiana de acarajé, que se torna um dos maiores ícones da cultura popular afro-brasileira, na cidade de Vitória da Conquista, na Bahia, nos séculos XX e XXI. A reconstrução da memória de Dona Dió do Acarajé nos levou a compreender a rede de relações sociais e culturais que se constituiu na criação do "Grupo Recreativo Escola de Samba União de São Vicente" e o processo de preservação e recriação das tradições culturais na valorização de símbolos da cultura popular local. A nossa abordagem é perscrutar, através da perspectiva do Standpoint Theory Feminist (COLLINS, 1989), o eixo interseccional (CRENSHAW, 2002) que articula as diversas diferenças e identidades - gênero-raça, classe e outras - presentes na trajetória social dessa mulher negra que, através do saber da cultura afro-brasileira e do trabalho, contribuiu para modificar práticas de exclusão social e transformar a sua história de vida e a de sua comunidade.
\end{abstract}

Palavras-chave: Mulheres negras. Interseccionalidade. Educação. Saberes afro-brasileiros.

\section{ABSTRACT}

\section{BLACK WOMEN: INTERSECTING GENDER, RACE, CLASS, CULTURE AND EDUCATION}

This article analyses the trajectory of a working class black woman, Baiana de Acarajé (a female Bahian vendor of sacred Acaraje street food), who, in the Bahian city of Vitoria da Conquista, transformed into one of the greatest icons of Afro-Brazilian popular culture of the $20^{\text {th }}$ and $21^{\text {st }}$ centuries. The reconstruction of the memory of Dona Dió do Acarajé enables us to understand the social and cultural relationships that came through with the creation of the "Recreational Group of the Samba School Union of São Vicente" and the way traditional cultures may be preserved and re-created by valuing the symbols of local popular culture. Our approach is to scrutinize, from the perspective of Feminist Standpoint Theory (COLLINS, 1989), the intersectional

\footnotetext{
* Professora Adjunta de Sociologia do Departamento de Educação da Universidade do Estado da Bahia (UNEB/Campus - I), Salvador, Bahia. Líder do Grupo de pesquisa CANDACES: gênero, raça, cultura \& sociedade, certificado pelo CNPq. Professora permanente do Programa de Pós-Graduação em Relações Étnicas e Contemporaneidade (PPGREC) da Universidade Estadual do Sudoeste da Bahia(UESB). ana_pachecau@hotmail.com

${ }^{* *}$ Mestranda do Programa de Pós-Graduação em Relações Étnicas e Contemporaneidade (PPGREC) da Universidade Estadual do Sudoeste da Bahia (UESB). Membro do Grupo de Pesquisa CANDACES: gênero, raça, cultura \& sociedade, certificado pelo CNPQ. mbnogueira07@hotmail.com
} 
axis (CRENSHAW, 2002) that brings together the range of differences and identities - gender, race, class and others - present in the social trajectory of this black woman who, through her knowledge of Afro-Brazilian culture and her work, helped to modify social exclusion practices and transform her life and community.

Keywords: Black women. Intersectionality. Education. Afro-Brazilian knowledge.

\section{RESUMEN}

\section{MUJERES NEGRAS INTERSEPCIONES GÉNERO, RAZA, CLASES, CULTURA Y EDUCACIÓN}

Este artículo analiza las trayectorias de una mujer negra de clase popular, baiana de acaraje, que se transformo en uno de los mayores iconos de la cultura popular afrobrasilera, en la ciudad de Victoria de Conquista, en la Bahía, en los siglos XX e XXI. La reconstrucción de la memoria de doña Dió do Acarajé nos llevo a comprender la rede de relaciones sociales e culturales que se constituyeron en la creación del "Grupo Recreativo Escuela de Samba União de São Vicente" y el proceso de preservación y recreación de las tradiciones culturales en la valoración de símbolos de la cultura popular local. Nuestro abordaje es estudiar minuciosamente a través de la perspectiva de Stand point Theory Feminist (COLLINS, 1989) el eje inter-seccional (CRENSHAW, 2002) que articula las diversas diferencias e identidades- género-raza, clase y otros - presentes en la trayectoria de esa mujer negra que, a través del saber de la cultura afro-brasilera y del trabajo, contribuyo para modificar prácticas de exclusión social e transformar su historia de vida y la de su comunidad.

Palabras claves: Mujeres negras. Interseccionalidad. Educación. Saberes afro-brasileros.

\section{A abordagem interseccional nos estudos sobre Mulheres Negras}

A utilização do conceito de interseccionalidade tem sido a tônica atual das pesquisas que procuram analisar a diversidade e as desigualdades existentes entre os sujeitos marcados no mínimo por dois ou mais eixos de opressão, sobretudo quando esses sujeitos são e têm sido os sujeitos dos feminismos - as mulheres. Como assinalou Kimberlé Crenshaw (2002), uma das propulsoras desse conceito no interior dos estudos feministas, a interseccionalidade é um conceito e uma abordagem metodológica que possibilita aos sujeitos cognoscentes analisarem as várias realidades existentes entre os grupos sociais historicamente excluídos. Outras teóricas feministas, nessa mesma linha, argumentam que o referido conceito tem sido uma saída epistemológica para resolver antigos impasses teóricos nas Ciências Humanas e Sociais e nos estudos de gênero, no que se refere ao dilema da Igualdade e da Diferença enquanto paradigmas explicativos em torno das análises que priorizam as teorias do sujeito moderno e da diversidade.

Desde o século passado que as Ciências Sociais vêm se debruçando em superar as antinomias herdadas pela filosofia ocidental e cartesiana no entendimento da dinâmica dos processos sociais em contextos contemporâneos que requerem novas abordagens conceituais e interdisciplinares referentes a temas que nos forçam a repensar um conjunto de ideias, valores, práticas e de produção de conhecimentos em torno das identidades culturais nos espaços da escola e fora dela.

Qualquer análise sobre os saberes dos grupos oprimidos deve, em primeiro lugar, creditar o lugar de fala dos grupos subalternizados (oprimidos) como sujeitos (produtores) de conhecimento sobre a sua própria realidade social e cultura local. Nesse sentido, os saberes construídos por esse agentes são ferramentas importantes de avaliação, criticidade e de mudança de paradigmas produzidos pela edu- 
cação hegemônica. Apostamos, assim como Freire (2005) e Collins (1989), que o ponto de vista do oprimido é a chave interpretativa e política dos fazedores da cultura popular contra o conhecimento hegemônico - androcêntrico, elitista, eurocêntrico - que permeia as instituições de ensino e que desvaloriza outras formas de saber produzidas pelos sujeitos subalternizados.

As possibilidades de pontos de vista (Standpoint Theory) dos sujeitos feministas aqui marcados por hierarquias e experiências histórico-sociais distintas endossam a crítica em relação ao conhecimento como algo distante da realidade. Os enunciados, narrativas, trajetórias e memórias dos sujeitos são valorizados nas formulações e posicionamentos das investigadoras em relação aos contextos com os quais se identificam e se diferenciam a depender das realidades abordadas; e, por último, o entendimento que os percursos e os espaços sociais são campos que se entrelaçam e se completam em várias dimensões complexas em que as desigualdades das relações de gênero, raciais e sociais são estruturantes e organizam as experiências vivenciadas dos agentes em processo de criação, invenção e modificação do habitus (BOURDIEU, 1986), em vários espaços sociais: escola, bairro, casa, rua, nas trajetórias e memórias do sujeito em questão. Dito isto, pretendemos com este artigo demonstrar: a) a importância da cultura popular (nesse caso, da cultura afro-brasileira) como estratégia de criação, educação, invenção e empoderamento de uma mulher negra de classe popular do interior da Bahia; b) as estratégias de superação e enfrentamento de Dona Dió do Acarajé frente às desigualdades de gênero, raça e classe presentes em sua trajetória social e na cultura local conquistense.

\section{$O$ pensamento feminista negro e o conhecimento popular afro-brasileiro}

No início da década de 1980, mulheres negras intelectuais começaram a formular conceitos e teorias no sentido de interpretar as várias opressões sofridas por mulheres negras estadunidenses, latinas e indígenas nas Américas e no Caribe. Esse movimento procurou criar epistemologias voltadas "não só para explicar como se formou nas Américas uma matriz de dominação sustentada pelo racismo, mas principalmente intervir e transformar essa realidade a partir de sua compreensão" (CARDOSO, 2014, p. 968). A ideia norteadora dessa epistemologia é levar em consideração as diversas experiências históricas das mulheres, sem anular os seus pontos de vista (standpoints) sobre as suas realidades materiais, comumente desconhecidas e ou distorcidas pelo conhecimento científico dominante.

Experiências concretas consideradas tarefas triviais que as mulheres executam no seu dia a dia, tais como: educar, cozinhar, cuidar da família e dos filhos, ou exercer o trabalho doméstico, são exemplos de atividades que podem lançar luz sobre as vidas e experiências de mulheres que até então foram subvalorizadas. As experiências concretas das mulheres possibilitam, por exemplo, identificar as diversas falhas nos sistemas socioeconômicos, além de apontar possíveis soluções a partir de suas vivências cotidianas no interior das macroestruturas. Como afirma Alison Jaggar (1997), ao exercer tais atividades, de cuidar e de educar, as mulheres desenvolveram um conjunto único de habilidades para lidar com a educação emocional e com a capacidade intuitiva e intelectual de ler e interpretar a dor e compreender a gênese dessas emoções.

Patrícia Hill Collins (1989), socióloga e ativista negra estadunidense, demonstrou por meio de depoimentos de mulheres negras comuns e de intelectuais maior possibilidade de interpretação teórica baseada na visão particular de cada sujeito sobre a sua realidade vivida. As suas pesquisas constataram que as mulheres negras têm um ponto de vista específico sobre os lugares sociais nos quais se situam; além disso, levantam questões políticas e epistemológicas que influenciam na construção social do pensamento negro e feminista:

A mulher africano-americana, como um grupo, tem
um mundo de experiências diferentes do que aqueles
que não são nem negros nem mulheres. [...] desta
forma, as experiências estimulam uma distinção da
consciência feminista negra relativa àquela reali-
dade material. Verifica-se que mulheres negras têm
apreendido esta conexão entre o que se faz e o que
se pensa. (COLLINS, 1989, p. 747-748).

Segundo Collins (1989), são dois níveis de conhecimento que estão impressos no ponto de vista das mulheres negras. O primeiro inclui o conhecimento do cotidiano embutido na vivência diária, 
no senso comum, e compartilhado pelo grupo; e o segundo é o conhecimento especializado de intelectuais que representam e expressam o ponto de vista do grupo subalternizado. A articulação desses dois níveis incentivam as mulheres negras a criarem novas autodefinições, partindo de elementos e temas das tradições e culturas afro-americanas associadas com o novo significado, "[...] o qual a consciência lhe dá outras ferramentas de resistência" (COLLINS, 1989, p. 50) A socióloga norte-americana Abigail Brooks (2007) compartilha dessa mesma concepção ao ressaltar a importância de pesquisas realizadas cujos primeiros resultados mostram como as mulheres vêm tomando consciência de suas histórias e de suas experiências, e começaram a reivindicar atenção nos diversos campos.

No Brasil, a tradição dos estudos sobre mulheres negras é recente. Como assinalam algumas autoras, tais estudos surgiram na academia a partir dos fins dos anos de 1970 e início dos anos de 1980 (BAIRROS, 1995; PACHECO, 2013; RIBEIRO, 1995). Esse período foi marcado pela organização política das mulheres negras e sua reivindicação pelo reconhecimento em torno de suas especificidades históricas, políticas e socioculturais na academia e na sociedade civil organizada.

A partir da década de 1990, os estudos sobre mulheres negras ampliaram-se. De acordo com a socióloga L. Caldwell (2010), na primeira década do século XXI pode-se afirmar que o campo de estudos de gênero e raça, no Brasil, ganhou uma dimensão significativa. Essa importância não se deu por acaso; ela se deu, em primeiro lugar, pela organização dos movimentos políticos das mulheres negras brasileiras, reivindicado reconhecimento, visibilidade e autonomia frente aos espaços sociais, educacionais, da política, da justiça e da academia. O segundo aspecto foi registrar - e esse é mais significativo para nós - a necessidade de construir um campo de conhecimento que investigasse as histórias das mulheres negras a partir de uma nova perspectiva epistemológica, em que nós mulheres negras pudéssemos ser sujeitos de conhecimento e de pesquisa. Aliada a essas duas abordagens, percebeu-se que a construção desse campo só seria válido à medida que esse "conhecimento situado" colocasse em suspensão as bases epistemológicas do racismo e do sexismo na produção das ciências (BAIRROS, 1995; CARNEIRO, 2002; HOOKS, 1995).

A crítica das feministas e intelectuais negras brasileiras possibilitou, nas últimas décadas, um conjunto de pesquisas sobre a situação social das mulheres negras, as várias formas de resistência histórica, cultural e política, os processos educacionais, as representações sociais nas artes e na literatura, e sua contribuição como portadora e partícipe da constituição e preservação dos valores civilizatórios africanos na sociedade brasileira. No campo da produção musical, as mulheres negras ainda habitam um lugar de sub-representação e de esquecimento face o seu papel ativo na preservação, na formação e na produção intelectual e social da cultura brasileira. A presença das mulheres negras nas Escolas de Samba tem sido uma dessas expressões culturais de protagonismo nas lutas de resistência cultural no cenário nacional e baiano, que, segundo Werneck (2007), precisa ser publicizada.

\section{A Escola de Samba e sua contribuição para a cultura popular}

"Batuque é um privilégio

Ninguém aprende samba no colégio

Sambar é chorar de alegria

É sorrir de nostalgia

Dentro da melodia" (NOEL ROSA, 1933).

Para refletir sobre a relação entre a cultura popular e as Escolas de Samba, consideraremos neste artigo dois aspectos importantes. Primeiro, adotamos a noção de educação popular desenvolvida por Paulo Freire (2005), aquela advinda dos grupos populares oprimidos em que os sujeitos são responsáveis pelo seu próprio fazer-saber e por sua própria cultura. ${ }^{1}$ Assim, entendemos que a escola de samba é uma forma de ensinamento e de aprendizado que produz conhecimentos situados, oriundos de experiências sociais as mais diversas, diferentemente do conhecimento "formal" ou hegemônico, que desconhece e deslegitima a diversidade de pensamento e de experiências das culturas subalternizadas, como a música, o samba, a

\footnotetext{
1 Para uma discussão pormenorizada das releituras acerca do conceito freireano de educação popular, ver edição, dossiê 43, da Revista FAEEBA sobre o tema Educação Popular(REVISTADAFAEEBA, 2015).
} 
capoeira e outras manifestações culturais. Segundo aspecto: acreditamos que a "cultura popular" é a transmissão e preservação de saberes oriundos das experiências e vivências das camadas subalternas, portanto exprimem um sentimento de identidade grupal. Dessa forma, o samba seria um gênero musical, historicamente originário no cotidiano e na intimidade das comunidades negras subalternizadas como forma de resistência cultural. Concordamos com a compreensão de Abib (2006, p. 08) quando afirma que

[...] os processos de transmissão de saberes presentes no universo da cultura popular têm como base para sua efetivação, a vivência em comunidade, pois só essa característica permite que os princípios [...] como a memória, a oralidade, a ancestralidade e a ritualidade possam ser enfatizados de maneira a garantir que os processos de aprendizagem social dos sujeitos se realizem com base na cultura e nas tradições daquele grupo social.

Traçar o contexto histórico do samba e suas escolas pode ser uma alternativa para melhor compreender como essa expressão popular, advinda da população negra e pobre, embora transformada em "produto" nacional assimilada por setores das elites e por interesses de diversos segmentos sociais, continua a ser um espaço de convergência e de produção de saberes das comunidades afro-brasileiras.

O livro Escola de Samba: a árvore que esqueceu a raiz, de Antonio Candeia Filho e Isnard Araújo (1978), ambos sambistas e fundadores da Escola de Samba Portela, no Rio de Janeiro, aponta para as vicissitudes enfrentadas dentro das escolas para manter a força da cultura afro-brasileira em toda a sua potencialidade. Sergio Cabral, ao prefaciar o livro, afirma que as escolas de samba hoje são utilizadas pelo potencial turístico, "sugadas pelo que oferecem de supérfluo e desprezadas pelo fundamental" (CANDEIA FILHO; ARAÚJO, 1978, p. VII) e acrescenta que o samba encontra-se atualmente sob as disputas de interesses mercadológicos, razões pelas quais divide a manifestação popular pura da ganância.

Há pessoas que não sabem, porém, que a vitória do samba - se assim pode chamar o que existe atualmente - pertence a uma parcela da população que sofreu violências, perseguições e preconceitos exclusivamente pelo "crime" de cantar, tocar e dançar esse mesmo samba (CANDEIA FILHO; ARAÚJO, 1978).

Vinculada aos segmentos populares, o samba em seu primeiro momento foi execrado pelas classes dominantes, até mesmo no carnaval, que se apresentava com grandes influências europeias. De acordo com Moura (1995), até meados do século $\mathrm{XX}$, em várias cidades do país, os ordenamentos jurídicos proibiam qualquer tipo de movimento que remetesse às tradições afro-brasileiras como o batuque, o samba e o candomblé. Na Bahia, desde 1853 que as manifestações negras foram deslocadas apenas para acontecer durante o período do carnaval baiano. Fora desse momento, tais manifestações eram perseguidas pela polícia em nome da ordem pública. Nesse período sugiram cordões e blocos com "intenções críticas" pelas ruas centrais da cidade, e que vão ressurgir no carnaval carioca.

Aparecem clubes carnavalescos liderados por africanos, crioulos e mestiços, já para o final do século, como a Embaixada Africana, os Pândegos da África, a Chegada da África e muitos outros. Através dos nomes, claro estava o sentido de afirmação cultural do passado africano, parte se identificando com egípcios, abissínios, aparentemente alheios às suas origens, mas a maioria com motivos da África negra (MOURA, 1995).

Segundo o sociólogo Roberto Moura (1995), em Salvador, os negros escravizados não perderam seus hábitos coletivistas, seus vínculos de linhagem e família, contudo, para sobreviver era preciso "repersonalizar", criar alternativas de resistência dentro de um sistema escravista: "Vindos de diversas procedências, irmanados pela cor da pele e pela situação comum, que redefinem suas tradições nessa sociedade paralela do mundo ocidental-cristão" (MOURA, 1995, p. 20). No início do século XX, as condições de trabalho não eram favoráveis para o contingente de trabalhadores livres em Salvador. Assim, "sob a bandeira branca de Oxalá", os negros baianos rumaram ao Rio de Janeiro, procurando um lugar para trabalhar e poder cultuar seus orixás.

Essa comunidade que vai se formando nos morros do Rio de Janeiro tem como sustentação as tias baianas "que eram responsáveis pela nova geração que nascia carioca, pelas frentes de trabalho, pela religião, rainhas negras de um Rio de Janeiro chamado por Heitor dos Prazeres de Pequena Áfri- 
ca.” (MOURA, 1995, p. 93). É então na casa de Hilária Batista de Jesus, a tia Ciata, a mais famosa e influente de todas as baianas que viveu no Rio de Janeiro naquele período (final do século XIX, início do século $\mathrm{XX}$ ), que surge o samba carioca. Grandes músicos como Pixinguinha, Donga, João da Baiana, Heitor dos Prazeres, dentre outros, têm nas rodas da casa de Tia Ciata a escola musical onde aprenderam, desde crianças, as tradições baianas.

Se o samba nasceu na Bahia, no Rio de Janeiro, em contato com outros valores da civilização moderna, modelou-se, começando a "diluir as fronteiras que se mostravam tão nítidas até então" (MOREIRA, 2013, p. 28). O samba intitulado Pelo Telefone, gravado em 1917, cuja autoria é controversa, foi o primeiro a "divulgar a ideia do samba como uma síntese de vários ritmos do folguedo popular e de expressões como maxixe e tango" (MOREIRA, 2013, p. 29). O novo formato do "samba urbano", com a introdução de objetos de percussão tais como surdos, tamborins e cuícas, apareceu com o bloco carnavalesco "Deixa Falar", criado por sambistas do bairro Estácio de Sá. Esta agremiação carnavalesca foi uma das muitas que surgiram na região portuária da cidade no final da década de 1920, considerada a primeira escola de samba do Rio de Janeiro.

De acordo com Cabral (1996), o samba carioca inicialmente estava reduzido aos morros, confinado nos terreiros e ao povo negro e pobre. Trabalhadores, estudantes, donas de casa, boêmios frequentavam as noitadas de festas nos morros onde surgiram diversos personagens próprios como o malandro, o boêmio, a tia-baiana, a mulata, a cabrocha, a pastora, que tinham seu palco principal as escolas de samba, além dos botequins e dos morros.

Segundo Moreira (2013), não se pode descartar os contornos e adaptações sofridas pelo samba, provenientes das exigências da sociedade naquele período histórico. Os ritmos das danças de salão, que tinham o perfil europeu, e as expressões musicais sincopadas dos grupos negros alteraram nos dois sentidos, tanto para as manifestações europeizadas quanto para as expressões rurais ou negras.

Nesse contexto, o samba já contava com aproximação entre os grupos negro-mestiços e frações da população intelectualizada. As mediações eram, então, estabelecidas num processo de aproximação e trânsito entre diferentes segmentos e domínios sociais, resultando em interações de múltiplos estilos de vida.

De fato, o samba teve uma rápida ascensão em razão da busca da elite política e cultural pelas "coisas nacionais"; como ressalta Munanga (1999), todos estavam empenhados em encontrar uma identidade étnica única para fazer do Brasil uma nação. O que estava em jogo neste debate intelectual nacional era, fundamentalmente, a questão de saber como transformar essa pluralidade de raças e mesclas, de culturas e valores civilizatórios tão diferentes, de identidades tão diversas, numa única coletividade de cidadãos, numa só nação, num só povo (MUNANGA, 1999).

As escolas de samba foram criadas dentro desse contexto histórico e, provavelmente, manter as raízes não seria sem vitupérios às tradições. A visibilidade, as disputas entre as escolas na avenida, a nacionalização, a exteriorização da cultura popular brasileira, a necessidade de promoção, até mesmo os enredos apresentados nas ruas, tudo contribuía para que as escolas fugissem da preocupação em defender o próprio samba e suas referências importantes para a sua cultura, como a origem na Bahia, nos morros do Rio de Janeiro, na comunidade negra. Contudo, atividades próprias das Escolas de Samba promoveram o envolvimento dos sambistas com a sua própria expressão cultural - o samba "como uma inequívoca demonstração de resistência ao imperativo social [...] e como uma afirmação de continuidade do universo cultural africano (SODRÉ, 1998, p. 12).

Candeia Filho e Araújo (1978) demonstram a necessidade de preservação da cultura popular nas escolas de samba:

Vamos nos colocar no chão com a cultura popular
brasileira, busca-la onde estiver: no morro, na Escola
de Samba, no bloco, no botequim, no terreiro, na rua,
nas rodas de samba e congêneres. Vamos respeitar
a arte popular, sem preconceito ou paternalismo,
tudo sem impor nada, respeitando sempre sua es-
pontaneidade, sua força original, sua criatividade.
(CANDEIA FILHO; ARAÚJO, 1978, p. 67-68).

Baseada nessa forma alternativa de pensar a sociedade, por meio das trajetórias dos agentes sociais, ou seja, dos deslocamentos sucessivos e da recriação e invenção dos habitus em vários es- 
paços socioculturais (BOURDIEU, 1986), temos o entendimento de que para reconstituir a memória de Dona Dió do Acarajé, uma mulher negra, baiana de acarajé, que viveu em Vitória da Conquista, no sudoeste baiano, será necessário analisarmos as redes sociais complexas às quais sua história está entrelaçada.

\section{A escola de Samba de Dona Dió do Acarajé}

Segundo a ativista negra e pesquisadora Jurema Werneck (2007, p. 271-272):

[Há] necessidade de transpor limites [...] de modo a alcançar outras possibilidades de visibilização e de leitura da participação das mulheres negras no mundo do samba [...] as ações de posicionamento cultural desenvolvidas pelas mulheres negras tiveram como base a atualização seletiva de elementos originados na tradição afro-brasileira que conferiam à mulher negra o papel de liderança.

Esse papel de liderança ao qual Werneck (2007) se refere podemos atribuir a Dionísia de Oliveira Silva, conhecida popularmente como Dona Dió do Acarajé, mulher negra, fundadora da Escola de Samba mais importante da cidade de Vitória da Conquista, na Bahia no século passado. Para realizar essa pesquisa, utilizamos os procedimentos metodológicos da história oral por meio de entrevistas orais, dialogando com registros fotográficos, documentos e jornais da época. O período da pesquisa se estendeu de agosto de 2015 a fevereiro de 2016, e foram realizadas 14 entrevistas com os filhos, amigos, colegas de trabalho, parentes simbólicos, componentes do grupo carnavalesco e promotores de eventos. Os registros dos nomes e as fontes foram autorizados pela família e por outros entrevistados, assim como a assunção das identidades das pessoas, que assinaram o Termo de Consentimento Livre e Esclarecido antes da realização da pesquisa. Vamos saber um pouco sobre a trajetória de Dona Dió do Acarajé.

Dona Dió é descendente de quilombolas da região da Lagoa de Maria Clemência, ${ }^{2}$ Rosalina Maria de Jesus e Pantaleão Américo de Oliveira. Nasceu na Rua do Triunfo, no Centro da cidade

2 Povoado que fica nos arredores da cidade de Vitória da Conquista. de Vitória da Conquista em abril de 1936, vindo a falecer em 07 de outubro de 2012, com 76 anos de idade, vivendo todo esse tempo na cidade de Vitória da Conquista. Casou-se por três vezes. O primeiro casamento aconteceu quando ela tinha 12 anos de idade. Logo separou e ficou com uma filha, que ela deu para uma família da elite política conquistense criar. Esta família mudou-se para o Rio de Janeiro levando a sua filha Joselita Santos. O segundo marido foi Albino Antônio da Silva, e com ele teve 13 filhos. Após viuvez, casou-se novamente com Pedro Luciano de Oliveira, com quem viveu até a sua morte. No total, Dona Dió teve 14 filhos, três faleceram, restando-lhe onze, entre os filhos biológicos e os de adoção.

De origem muito pobre, Dona Dió interrompeu os estudos porque precisava trabalhar. Inicialmente, exerceu a ocupação de lavadeira, e, continuamente, sobreviveu com a venda de produtos alimentícios nas portas de clubes, bares e hotéis. Mais tarde, inseriu-se no mercado informal, através da venda de acarajé. $\mathrm{O}$ acarajé foi definitivamente o seu meio de sobrevivência socioeconômica mais importante. Através desse alimento, Dona Dió criou uma verdadeira rede de sustentação econômica para sua família (marido e filhos); tal atividade lhe possibilitou estabelecer outras redes de empoderamento social e simbólico, tais como sua vinculação religiosa com os cultos afro-brasileiros e sua relação com o samba e outras redes de relações sociais e políticas mais amplas na cidade conquistense.

A reconstituição da trajetória de Dona Dió foi possível devido à memória coletiva que existe em torno de sua presença imaterial, enquanto patrimônio cultural e simbólico. É essa memória que nos propomos a investigar. De acordo com a antropóloga brasileira Lélia Gonzales (1984), para compreender e apontar o lugar das mulheres negras no processo de formação cultural e educacional é importante trabalhar com duas noções: a de consciência e a de memória.

Como consciência a gente entende o lugar do desconhecimento, do encobrimento, da alienação, do esquecimento e até do saber. É por aí que o discurso ideológico está presente. Já a memória, a gente considera como o não-saber que conhece, esse lugar de inscrições que restituem uma história que não foi escrita, o lugar da emergência 
da verdade, dessa verdade que se estrutura como ficção. Consciência exclui o que a memória inclui (GONZALES, 1984).

As memórias sobre Dona Dió apontam para uma conquista proveniente de tradições culturais afro-indígenas que foram reconhecidas nas suas formas de articular com os diversos poderes institucionalizados, bem como com a sociedade de forma geral. Após a sua morte, ${ }^{3}$ dentre os eventos que comemoravam a "semana da consciência negra" daquele ano, a vida de Dona Dió foi lembrada como uma representação do "povo negro" da cidade. No Centro Cultural Camilo de Jesus Lima, ao som da música de Dorival Caymmi A preta do acarajé, um grupo de teatro encenou lembranças do cotidiano de Dona Dió, e vários utensílios que marcaram a sua vida foram expostos no saguão do centro cultural.

De acordo com Stuart Hall (2003, p. 54), "precisamos encontrar formas de manifestar publicamente a importância da diversidade cultural, e de integrar as contribuições das pessoas de cor ao tecido da sociedade". Essa ideia fez parte do cotidiano de Dona Dió do Acarajé. Mesmo antes de ser "baiana de acarajé", Dona Dió esteve envolvida em movimentos que traziam à cena a cultura afro-brasileira. Desde adolescente participava das batucadas que aconteciam nos bairros periféricos, e que se apresentavam nos carnavais pelas ruas centrais da cidade. Segundo depoimentos, esses eventos eram, para Dona Dió, não apenas uma forma de divertimento, mas uma maneira de integrar os negros na vida social.

Dona Dió e seu filho participavam da Batucada Imperadores do Samba, que era dirigida por Antônio Pereira de Souza, conhecido como Choro Baixo. Quando Choro Baixo resolveu desistir da batucada, seu filho pediu emprestado os instrumentos, pois queria, ele mesmo, ainda com 12 anos de idade, continuar com o empreendimento da mãe. Se o seu filho gostava de festa e de samba, ela continuava ávida por atividades que permitissem desenvolver suas habilidades de socialização. Sendo assim, contando com sua habilidade, ela articulou com a prefeitura para conseguir verbas e custear as fantasias; tal fato possibilitou a realização do desfile nos carnavais conquistenses naquele período. Segundo o relato de seu filho Albino (2015):

3 Dona Dió morreu em outubro de 2012.
A batucada era de um amigo da gente e a gente participava junto com ele. Depois ele desistiu de continuar. Ai eu pedi os instrumentos emprestado e ele passou pra gente e a gente começou com essa batucada e ensaiava no quintal da casa da minha mãe. As pessoas falavam: "um menino desses vai ter condições de tocar um negócio desse aqui?" ai, mas só que só tinha eu que tinha doze ou treze anos, o resto era adulto. Então eu assumi, e a gente foi fazendo essa batucada.

Segundo Roberto Moura (1995, p. 41), o batuque foi o nome dado pelo português às danças africanas que na Bahia tomam forma de "dança-luta", acontecendo aos domingos em alguns bairros de Salvador. "O samba de roda nas festas de rua em Salvador onde os batuqueiros respondiam aos refrões conhecidos [...] refrões que se celebrizam contestados pelos improvisos de cada um". Mesmo com as proibições e permissões, o batuque deu origem a vários ritmos e danças como o samba de roda e a capoeira, a polca, o lundu, o maxixe, dentre outros.

De acordo com Lemos (2001), vários foram os motivos que levaram à fragmentação das Batucadas. Dentre eles estavam as forças mais jovens, com novos elementos, para evitar a estagnação das Batucadas. Uma das propostas era a de trazer para as ruas o samba-enredo carioca, que um dos participantes vivenciou no Rio de Janeiro ao visitar diversas escolas de samba. Os cordões de batucadas continuaram a fazer parte dos festejos carnavalescos até 1978, quando foram transformados em Escolas de Samba como uma forma de resistência que afirmava as manifestações populares do ritmo afro-brasileiro em Vitória da Conquista.

Dona Dió e sua equipe não pararam no tempo e criaram condições para transformar a Batucada Imperadores do Samba no Grupo Recreativo Escola de Samba União de São Vicente, "uma sociedade dos cultivadores do carnaval de Vitória da Conquista". Assim declara o Projeto de Lei $n^{\circ}$ 434/88 da Câmara Municipal. A Escola de Samba União de São Vicente foi fundada em outubro de 1981 e teve como sede a residência de Dona Dió, situada na Rua da Conceição, 90, Bairro de São Vicente, em Vitória da Conquista. Era no quintal da casa que aconteciam os ensaios, sob a direção do seu filho Albino e com a participação de toda a família e amigos. 
A escola de samba se apresentou como uma atualização das batucadas, uma proposta que fosse capaz de envolver antigos e novos batuqueiros, que apresentasse uma forma de gestão capaz de contemplar as diversas vozes que desejavam construir uma participação mais bonita e animada nos carnavais, que se constituísse numa força capaz de elaborar novas soluções visuais e rítmicas partindo das contribuições recebidas das antigas lideranças (LEMOS, 2001).

Embora as escolas de samba surgissem na avenida em 1979, somente no final da década de $1980^{4}$ que começaram a ser reconhecidas como entidades de utilidade pública. O título de Utilidade Pública Municipal dava à entidade o direito de receber verbas oriundas de subvenções sociais da Câmara de Vereadores. Para tanto era necessária a comprovação de que não existissem fins lucrativos, tivesse prestado relevantes serviços à comunidade na sua área de atuação por pelo menos um ano e ainda não praticasse discriminação de raça, credo, sexo ou filosófica. ${ }^{5}$

Os associados do grupo carnavalesco não tinham condições de comprar as fantasias ou mesmo colaborar com alguma despesa. Nesse momento é que Dona Dió, como tesoureira e "matrona" do grupo, articulava com os órgãos públicos municipais para angariar fundos. Viajava até o Rio de Janeiro para comprar fantasias e trazer modelos para os desfiles. A verba doada pela Prefeitura nunca dava para cobrir todas as despesas, então eram as vendas dos acarajés que bancavam toda aquela "beleza" que descia pelas ruas da cidade durante os carnavais, ganhando sempre as premiações oferecidas. De acordo com Edneide, uma de suas filhas, isso acontecia porque:

Então ela trabalhava. Às vezes a prefeitura dava uma ajuda de custo, mas, a batucada ganhava todo ano, mas era ela que ia trabalhar pra pagar seu Otávio os tecidos que comprava para fazer as roupas, pagar as costureiras. [...] Depois ela comprava os tecidos, depois ia trabalhar no acarajé para pagar. Para fazer bonito pra prefeitura. [risos] [...] Mas era uma coisa que ela gostava e a gente não podia, não podia contrariar porque ela gostava. (EDNEIDE, 2015).

\footnotetext{
4 Esse fato é observado nos processos para reconhecimento de utilidade pública.

5 Lei $\mathrm{n}^{\circ} 462 / 88$ - APMVC
}

De acordo com as filhas de Dona Dió, elas passavam a madrugada costurando as fantasias, trabalhavam a noite toda para dar conta do serviço. Com o crescimento da escola, tornou-se necessária a contratação de costureiras. Na época do carnaval, a casa de Dona Dió ficava cheia de hóspedes. Ela trazia pessoas influentes do Rio de Janeiro, de Pedra Azul, de Almenara para desfilarem na escola de samba, além dos muitos amigos. Tudo era muito bem elaborado, razão pela qual, durante vários anos, a premiação do primeiro lugar esteve com o Grêmio Recreativo Escola de Samba União de São Vicente.

Em abril de 1988, por meio do Projeto de Lei 434/88, fica declarado de utilidade pública o Grêmio Recreativo União de São Vicente, tendo como objetivos gerais promover festas carnavalescas, participar e competir em desfiles, congregar pessoas que se dediquem à cultura das Escolas de Sambas. Neste sentido, o grupo deveria promover concursos, festivais, conferências, seminários, exposições, pesquisas e estudos que possibilitassem o desenvolvimento cultural e festivo dos associados e da região, incentivando o interesse pelos assuntos carnavalescos e pela cultura afro.

Durante vários anos, enquanto a festa carnavalesca existia em Vitória da Conquista, a escola de samba de Dona Dió do Acarajé esteve na avenida, como retratam os versos de Noé Moreno: 6 "a União de São Vicente, é festa do povo, cultura popular [...] Dió, figura importante na cidade, sempre trouxe pra Avenida, grandes histórias, realidades". Percebemos que esse evento proporcionado por Dona Dió do Acarajé marcou a presença afro-brasileira na história da cidade, por meio da resistência político-cultural da comunidade, no reconhecimento e na reafirmação de várias identidades.

Entendemos que a Escola de Samba constituiu uma das maiores manifestações da cultura popular nos carnavais conquistenses e representa o resgate do legado da cultura afro-brasileira por anunciar um processo social de resistência e continuação de um saber popular que demonstra um rompimento com o embranquecimento cultural e práticas discriminatórias que invisibilizam os fazedores de

\footnotetext{
6 Compositor da cidade, escreveu essa letra em homenagem a Dona Dió e a Escola de Samba União de São Vicente, a escola formada por Dona Dió e seu filho nos anos de 1980.
} 
culturas e sua importância histórico-antropológica na produção dos saberes dos grupos subalternizados. A escola de samba de Dona Dió foi mais que um espaço recreativo, festivo; através dela gerou-se trabalho social para a comunidade, espaços de socialização e de aprendizado para os mais jovens e registrou-se na memória da sociedade conquistense as marcas de sua ancestralidade africana que o tempo não deverá apagar.

\section{Considerações finais}

Consideramos todas essas maneiras e hábitos que constituem o cotidiano da comunidade das escolas de samba uma forma de transmissão de conhecimento capaz de inserir jovens marginalizados no convívio social por meio de outras formas de saber e conscientização de valores em um processo educativo. Uma forma de educação libertadora no sentido freiriano, que possibilita o diálogo constante com o outro e permite a "discussão corajosa de sua própria problemática” (FREIRE, 1997, p. 90). Uma forma de educação que visa transformar o indivíduo em agente político, capaz de modificar a sua história e recuperar valores, tradições, conhecimentos que, na maioria das vezes, as instituições escolares se negam a contar. Segundo essa lógica freireana, reiteramos a importância do ponto de vista das teorias do feminismo negro. Segundo Collins (1989), a história das mulheres negras deverá ser analisada a partir das suas experiências sociais e históricas concretas, respeitando suas identidades e diferenças de classe, raça, etnia e de visões de mundo com as quais aprenderam e construíram o saber cotidiano da sobrevivência e da cultura popular.

\section{REFERÊNCIAS}

ABIB, Pedro Rodolpho Jungers. Cultura popular, educação e lazer: uma abordagem sobre a capoeira e o samba. Praxis Educativa, Ponta Grossa, PR, v. 1, n. 1, p. 58-66, 2006. Disponível em: <http://www.revistas2.uepg.br/ index.php/praxiseducativa/article/view/245/248>. Acesso em: 15 fev. 2016.

BAIRROS, Luisa. Nossos feminismos revisitados. Revista Estudos Feministas - Dossiê Mulheres Negras, Rio de Janeiro, v. 3, n. 2, p. 458-463, 1995.

BOURDIEU, Pierre. L'illusion biographique. Actes de la Recherche en Sciences Sociales, Paris, n. 62/63, juin, 1986.

BROOKS, Abigail. Feminist standpoint epistemology: building knowledge and empowerment through women's lived experience. In: HESSE-BIBER, Sharlene Nagy; LEAVY, Patricia Lina (Ed.). Feminist research practice. London: Sage, 2007. p. 53-82. Disponível em: <http://srmo.sagepub.com/view/feminist-research-practice/n3.xml >. Acesso em: 15 maio 2015.

CABRAL, Sérgio. As escolas de samba do Rio de Janeiro. Rio de Janeiro: Lumiar, 1996.

CALDWELL, Kia Lilly. A institucionalização de estudos sobre a mulher negra: perspectivas dos Estados Unidos e do Brasil. Revista ABPN, v. 1, n. 1, p.18-27, mar./jun. 2010.

CANDEIA FILHO, Antônio; ARAÚJO, Isnard. Escola de samba - árvore que esqueceu a raiz. Rio de Janeiro: Lidador/Secretaria Estadual de Cultura, 1978.

CARDOSO,Cláudia Pons. Amefricanizando o feminismo: o pensamento de Lélia Gonzalez. Revista Estudos Feministas, Florianópolis, v. 22, n. 3, p. 965-986, set./dez. 2014. Disponível em: <https://periodicos.ufsc.br/index. php/ref/article/view/36757/28579>. Acesso em: 04 out. 2015.

CARNEIRO, Suely. Enegrecer o feminismo: a situação da mulher negra na América Latina a partir de uma perspectiva de gênero. São Paulo: UNIFEM, 2002. Disponível em: <http://www.unifem.org.br/sites/700/710/00000690. pdf $>$. Acesso em: 10 abr. 2015.

COLLINS, Patricia Hill. The social construction of black feminist thought. Signs, v. 14, n. 4, p. 745-773, Summer, 1989. Disponível em: <http://www.jstor.org/stable/317463>. Acesso em: 14 abr. 2015.

CRENSHAW, Kimberlé. Documento para o Encontro de Especialistas em Aspectos da Discriminação Racial Relativos ao Gênero. Estudos Feministas, n. 01, p. 171-263, 2002.

FREIRE, Paulo. Educação como prática da liberdade. Rio de Janeiro: Paz e Terra, 1997. 
Pedagogia do oprimido. Rio de Janeiro: Paz e Terra, 2005.

GONZALES, Lélia. Racismo e sexismo na cultura brasileira. Revista Ciências Sociais Hoje, Rio de Janeiro, p. 223-244, 1984.

HALL, S. Da diáspora: identidades e mediações culturais. Tradução Adelaine La Guardia Resende. Belo Horizonte: Editora UFMG, 2004.

HOOKS, B. Intelectuais negras. Revista Estudos Feministas, v. 3, n. 2, p. 454-478, 1995.

JAGGAR, Alison M. Amor e conhecimento: a emoção na epistemologia feminista. In: JAGGAR, Alison M.; BORDO, Susan R. (Org.). Género, corpo, conhecimento. Tradução de Brítta Lemos de Freitas. Rio de Janeiro: Record, 1997. p. 157-184.

LEMOS, Rosalvo. As batucadas em Vitória da Conquista: identidades culturais, ritmos e representações. 2001. Dissertação (Mestrado em Memória Social e Documento) - Programa de Pós-Graduação em Memória Social, Universidade Federal do Rio de Janeiro, 2001.

MOREIRA, Núbia Regina. A presença das compositoras no samba carioca: um estudo da Trajetória de Teresa Cristina. 2013. Tese (Doutorado em Sociologia) - Programa de Pós-Graduação em Sociologia, Instituto de Ciências Sociais, Universidade de Brasília, 2013.

MOURA, Roberto. Tia Ciata e a pequena África no Rio de Janeiro. Rio de Janeiro: Secretaria Municipal de Cultura, 1995.

MUNANGA, K. Rediscutindo a mestiçagem no Brasil: identidade nacional versus identidade negra. Petrópolis, RJ: Vozes, 1999.

PACHECO, Ana Cláudia Lemos. Mulher negra: afetividade e solidão. Salvador: EDUFBA, 2013.

REVISTA DA FAEEBA. Salvador, UNEB, v. 24, n. 43, jan./jun. 2015.

RIBEIRO, Matilde. Mulheres negras brasileiras: de Bertioga a Beijing. Estudos Feministas, Rio de Janeiro, ano 3, n. 2, p 446-457, 1995.

ROSA, Noel. Feitio de oração. Rio de Janeiro, 1933. Disponível em: <https://www.letras.mus.br/noel-rosa-musicas/535516/>. Acesso em: 10 abr. 2015.

SODRÉ, Muniz. Samba, o dono do corpo. Rio de Janeiro: Mauad, 1998.

WERNECK, Jurema. O samba segundo as ialodês: mulheres negras e a cultura midiática. 2007. Tese (Doutorado em Comunicação e Cultura) - Programa de Pós-Graduação em Comunicação, Universidade Federal do Rio de Janeiro, 2007.

Recebido em: 30.11 .2015

Aprovado em: 01.03 .2016 